\title{
Safety and tolerability of conditioning chemotherapy followed by CD19-targeted CAR T cells for relapsed/refractory CLL
}

Mark B. Geyer, ${ }^{1,2}$ Isabelle Rivière, ${ }^{2,3,4}$ Brigitte Sénéchal, ${ }^{3,4}$ Xiuyan Wang, ${ }^{2,3,4}$ Yongzeng Wang, ${ }^{3}$ Terence J. Purdon, ${ }^{1}$ Meier Hsu, ${ }^{5}$ Sean M. Devlin, ${ }^{5}$ M. Lia Palomba, ${ }^{1,2}$ Elizabeth Halton, ${ }^{1}$ Yvette Bernal, ${ }^{1}$ Dayenne G. van Leeuwen, ${ }^{1}$ Michel Sadelain, ${ }^{2}$ Jae H. Park, ${ }^{1,2}$ and Renier J. Brentjens ${ }^{1,2,4}$

'Department of Medicine, ${ }^{2}$ Center for Cell Engineering, ${ }^{3}$ Michael G. Harris Cell Therapy and Cell Engineering Facility, ${ }^{4}$ Molecular Pharmacology and Chemistry Program, and ${ }^{5}$ Biostatistics, Memorial Sloan Kettering Cancer Center, New York, New York, USA.

BACKGROUND. Subgroups of patients with relapsed or refractory $(R / R)$ chronic lymphocytic leukemia (CLL) exhibit suboptimal outcomes after standard therapies, including oral kinase inhibitors. We and others have previously reported on the safety and efficacy of autologous CD19targeted CAR T cells for these patients. Here, we report safety and long-term follow-up of CAR T cell therapy with or without conditioning chemotherapy for patients with R/R CLL and indolent $B$ cell non-Hodgkin lymphoma (B-NHL).

METHODS. We conducted a phase I clinical trial investigating CD19-targeted CAR T cells incorporating a CD28 costimulatory domain (19-28z). Seventeen of twenty patients received conditioning chemotherapy prior to CAR T cell infusion. Five patients with CLL received ibrutinib at the time of autologous T cell collection and/or CAR T cell administration.

Authorship note: JHP and RJB are co-senior authors.

Conflict of interest: MBG has received an honorarium from DAVA Oncology. JHP has consulted and played an advisory role for Amgen and Juno Therapeutics and has received research funding from Juno Therapeutics and Genentech/Roche. IR and R|B have consulted and played an advisory role for, have a royalty sharing agreement with, have research funding from, and own stock in Juno Therapeutics. MS has consulted and played an advisory role for, has a royalty sharing agreement with, and owns stock in Juno Therapeutics.

Role of funding source: Juno Therapeutics provided financial support for this clinical trial, including product manufacturing (performed at Memorial Sloan Kettering).

Copyright: (ㄷ) 2019 American Society for Clinical Investigation

Submitted: January 16, 2019 Accepted: March 27, 2019

Published: May 2, 2019.

Reference information: /Cl Insight. 2019;4(9):e122627. https://doi. org/10.1172/ji.insight.122627.
RESULTS. This analysis included 16 patients with R/R CLL and 4 patients with R/R indolent $B-N H L$. Cytokine release syndrome (CRS) was observed in all 20 patients, but grade 3 and 4 CRS and neurological events were uncommon ( $10 \%$ for each). Ex vivo expansion of $\mathrm{T}$ cells and proportions of CAR T cells with the CD62L+CD127+ immunophenotype were significantly greater $(P=0.047$; CD8 subset, $P=0.0061, C D 4$ subset) in patients on ibrutinib at leukapheresis. Three of twelve evaluable CLL patients receiving conditioning chemotherapy achieved complete response (CR) ( 2 had minimal residual disease-negative $(\mathrm{R})$. All patients achieving $\mathrm{CR}$ remained progression free at median follow-up of $\mathbf{5 3}$ months.

CONCLUSION. Conditioning chemotherapy and 19-28z CAR T cells were acceptably tolerated across investigated dose levels in heavily pretreated patients with R/R CLL and indolent B-NHL, and a subgroup of patients achieved durable CR. Ibrutinib therapy may modulate autologous T cell phenotype.

TRIAL REGISTRATION. ClinicalTrials.gov NCT00466531.

FUNDING. Juno Therapeutics and NIH/National Cancer Institute Cancer Center Support Grant (P30-CA08748).

\section{Introduction}

Chronic lymphocytic leukemia (CLL) is the most prevalent adult leukemia in Western countries, and over 20,000 patients are newly diagnosed annually in the United States $(1,2)$. The natural history of CLL is considerably heterogeneous, though the majority of patients eventually require treatment for progressive lymphadenopathy, organomegaly, or BM failure. While a subset of patients achieve durable complete response (CR) following combination chemoimmunotherapy, this standard treatment of CLL is rarely curative, and most patients experience subsequent progression (3). Additionally, in patients who exhibit high-risk features, including unmutated $\mathrm{IgH}$ variable region (IgHV), deletion of $17 \mathrm{p}$, or loss of TP53, the duration of response 
to chemoimmunotherapy is suboptimal (4-8). While oral molecularly targeted kinase inhibitors ibrutinib or idelalisib can be effective lines of further therapy, in patients with CLL who have a $17 \mathrm{p}$ deletion, complex karyotype, or had prior CLL treatment, median progression-free survival is $\leq 3$ years following initiation of these drugs. Additionally, outcomes following CLL progression on first-line kinase inhibitor therapy are dismal - median progression-free survival is $\leq 10$ months, even in the era of sequential targeted therapies (9-11). As such, subgroups of patients with CLL remain in need of novel therapeutic strategies.

We and others have reported on the use of CD19-targeted chimeric antigen receptor-modified (CAR-modified) autologous $\mathrm{T}$ cells bearing a 4-1BB or CD28 costimulatory domain in patients with relapsed or refractory (R/R) CLL, demonstrating safety, tolerability, and in vivo persistence and expansion (12-18). While CD19-targeted CAR T cell therapy achieves rates of minimal residual disease-negative (MRD-negative) $\mathrm{CR}$ exceeding $70 \%$ in some series investigating it in $\mathrm{R} / \mathrm{R}$ B cell acute lymphoblastic leukemia (B-ALL) (18-25), mature series investigating this therapy in R/R CLL have reported CR rates $<30 \%$, though durable MRD-negative $\mathrm{CR}$ is observed in a small subset of patients $(14,17)$.

We previously reported outcomes from the first 8 patients with R/R CLL treated on a phase I trial at our institution. No objective responses were observed in that cohort after therapy with CD19-targeted CAR T cells containing a CD28 costimulatory domain (19-28z) (16). This phase I trial began as a CAR $\mathrm{T}$ cell dose escalation study and was subsequently modified to optimize conditioning chemotherapy (based in part on emerging reports that fludarabine (Flu) may enhance CAR T cell expansion $(12,26)$ to include patients with indolent B cell non-Hodgkin lymphoma (B-NHL) and to permit ongoing therapy with ibrutinib at the time of autologous $\mathrm{T}$ cell collection and CAR $\mathrm{T}$ cell infusion. The primary objective of the study was to evaluate the safety and toxicity of $19-28 \mathrm{z}$ CAR T cell therapy with or without conditioning chemotherapy. Herein, we report safety data and long-term follow-up of 20 patients with R/R CLL and indolent B-NHL treated with 19-28z CAR T cells, including the 8 patients in the aforementioned series (16), and discuss the potential implications of ibrutinib on CAR T cell manufacturing and phenotype. CAR T cell doses as high as $3 \times 10^{7} 19-28 \mathrm{z}$ CAR T cells $/ \mathrm{kg}$, infused following one of several regimens of conditioning chemotherapy, were acceptably tolerated in heavily pretreated patients with R/R CLL and indolent B-NHL. In a subset of patients, this approach was associated with robust in vivo expansion and durable MRD-negative $C R$, even in the absence of detectable long-term CAR T cell persistence.

\section{Results}

Patient characteristics. Demographic and clinical characteristics of patients with R/R CLL and indolent B-NHL, respectively, are shown in Tables 1 and 2. Study design and conduct is detailed within the Methods. Dose-limiting toxicities (DLT) and cytokine release syndrome (CRS) grading criteria, respectively, are summarized in Supplemental Tables 1 and 2 (supplemental material available online with this article; https://doi. org/10.1172/jci.insight.122627DS1). The study enrolled 50 patients; 27 patients received CAR T cell therapy on study, and 20 are included in this analysis (Figure 1). The 7 CAR T cell recipients excluded from this report received 19-28z CAR T cells in addition to another cellular product $(n=5)$ or had a diagnosis of Waldenström macroglobulinemia $(n=2)$. This analysis included 16 cases of R/R CLL and 4 cases of R/R B-NHL (marginal zone lymphoma, $n=2$; follicular lymphoma, $n=1$; mantle cell lymphoma, $n=1)$. Patients were $70 \%$ male (14 of 20), and the median age at first CAR T cell infusion was 63 years (range, $43-75$ years). The disease burden of each patient at the time of CAR T cell infusion is described in Supplemental Table 3. Of the 23 patients enrolled to the study who did not receive 19-28z CAR T cells, 17 (74\%) elected to pursue alternative therapy, $2(9 \%)$ were ultimately treated on an alternative CAR T cell trial, and $1(4 \%)$ resumed observation; 3 patients (13\%) died prior to planned 19-28z CAR T cell therapy.

Among the CLL patients, 9 had unmutated IgHV. Additional molecular and cytogenetic abnormalities observed in the patients with CLL included deletion of 11q $(n=5)$, deletion of 17p or loss of TP53 $(n=4)$, and complex karyotype $(n=3)$. Patients had received a median of 4 prior lines of therapy (range, 1-11 lines). Specific therapies administered to each CLL patient prior to CAR T cell therapy are detailed in Supplemental Table 4. Six patients with CLL had received ibrutinib therapy prior to CAR $\mathrm{T}$ cell infusion, including continuously prior to leukapheresis $(n=4$ for median 4.8 months; range, 2.0-15.5 months) and continuously prior to CAR T cell infusion ( $n=5$ for median 7.0 months; range, 3.5-18.5 months) (Supplemental Figure 1). Four patients with B-NHL had received a median of 8 prior lines of therapy (range, 6-10 lines). 


\begin{tabular}{|c|c|c|c|c|c|c|c|c|c|c|c|c|c|c|c|c|}
\hline 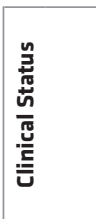 & 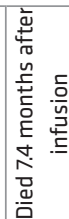 & 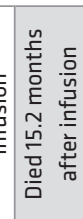 & 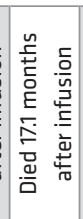 & 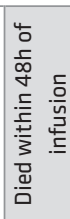 & 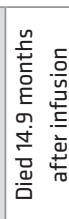 & 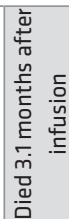 & 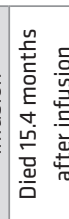 & 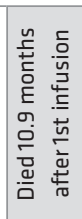 & 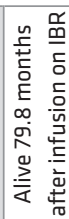 & 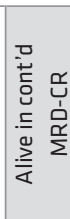 & 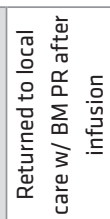 & 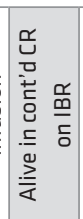 & 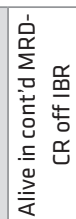 & 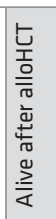 & 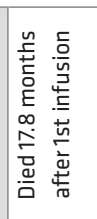 & 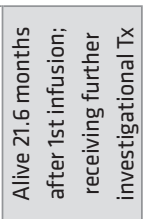 \\
\hline 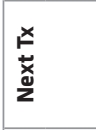 & 竞 & ฮ్ & 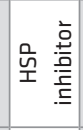 & $\frac{\pi}{z}$ & $\sum_{\substack{\alpha \\
\alpha}}^{n}$ & 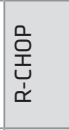 & $\sum_{\substack{\alpha \\
\alpha}}^{a}$ & 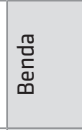 & 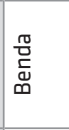 & $\frac{\dddot{0}}{2}$ & 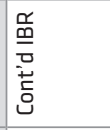 & 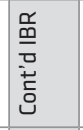 & $\frac{0}{\stackrel{0}{2}}$ & $\begin{array}{l}\text { 우 } \\
\text { 옴 } \\
\dot{\alpha}\end{array}$ & $\stackrel{5}{D}$ & 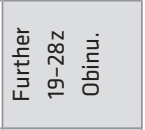 \\
\hline 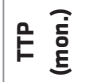 & $\stackrel{丶}{\rightleftharpoons}$ & $\bar{i}$ & $\stackrel{n}{N}$ & एu & $\bar{m}$ & $\stackrel{\text { !n }}{\square}$ & $\hat{m}$ & 湈 & $\stackrel{\infty}{\stackrel{\infty}{\rho}}$ & 柋 & 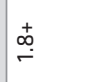 & 柋 & $\begin{array}{l}\stackrel{+}{+} \\
\stackrel{g}{q}\end{array}$ & mo & 崖 & $\stackrel{\leftrightarrow}{N} \stackrel{\stackrel{g}{\circ}}{\leftarrow}$ \\
\hline 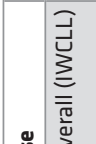 & 몽 & ㅁ & 몸 & 岸 & и & 몸 & in & in in & 只 & $\begin{array}{l}\text { ㅁ } \\
\dot{y} \\
\dot{\alpha} \\
\frac{\alpha}{\Sigma}\end{array}$ & जि & $\begin{array}{l}\text { 品 } \\
+ \\
\text { 䍃 }\end{array}$ & $\begin{array}{l}\text { 号 } \\
\dot{d} \\
\text { 容 }\end{array}$ & 몽 & 岁 品 & 岁 品 $\frac{\omega}{z}$ \\
\hline
\end{tabular}

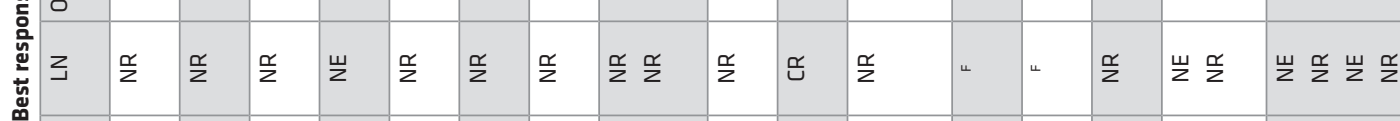

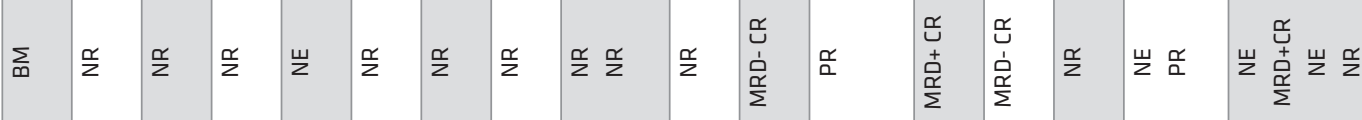

\begin{tabular}{|l|l|l|l|l|l|l|l|l|l|l|l|l|l|l|l|l}
\hline \\
\hline
\end{tabular}

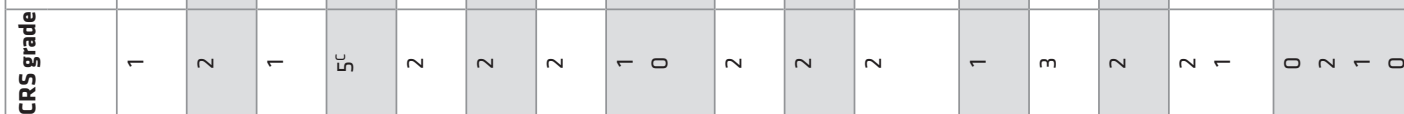

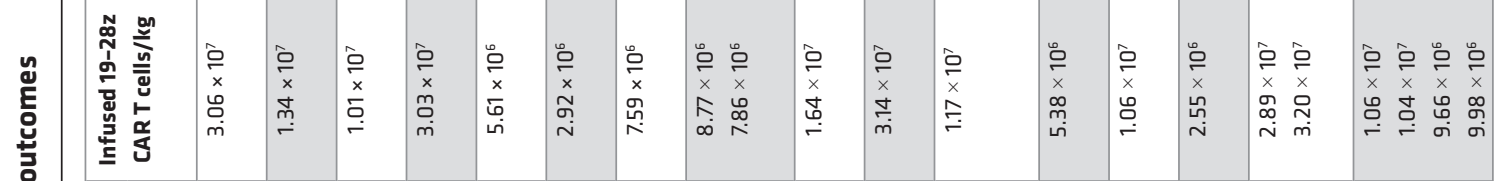

\begin{tabular}{|c|c|c|c|c|c|c|c|c|c|c|c|c|c|c|c|}
\hline 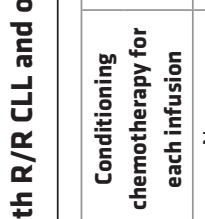 & 产 & $\frac{0}{\tilde{0}}$ & 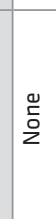 & 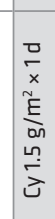 & 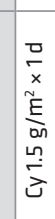 & 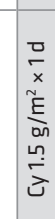 & 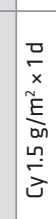 & 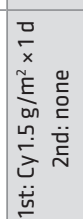 & 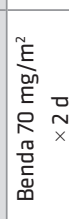 & 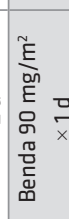 & 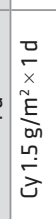 & 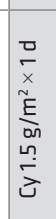 & 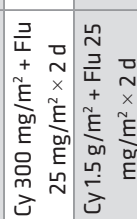 & 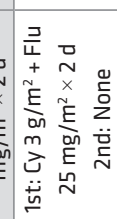 & 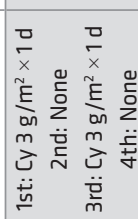 \\
\hline
\end{tabular}

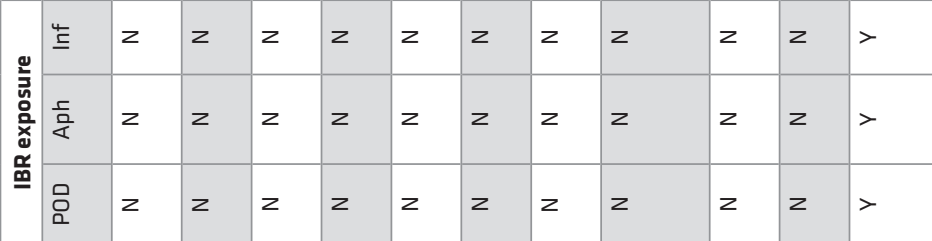

率:

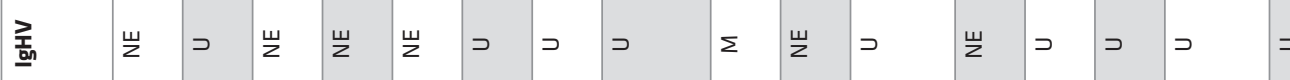

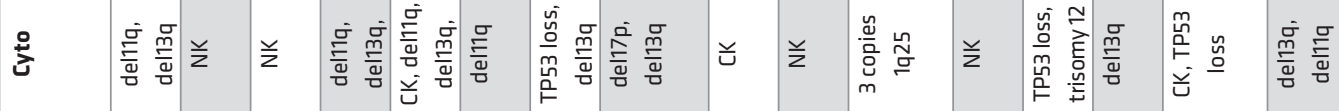

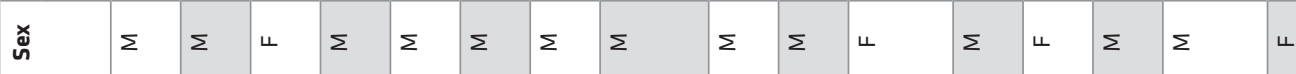

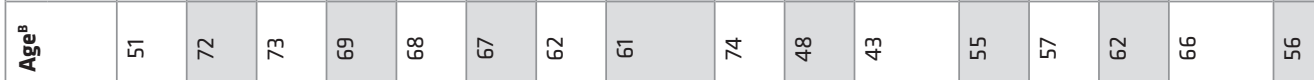

高要离

$\ddot{a}$

$\lesssim \quad \stackrel{m}{\sim} \quad \stackrel{m}{\sim}$

$m$

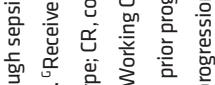

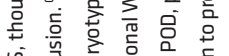

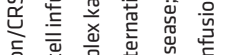

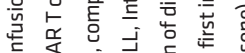

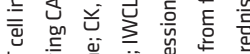

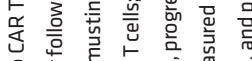

음

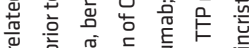

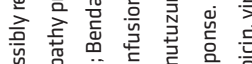

总

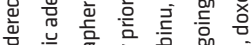

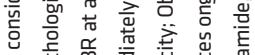

吾兽

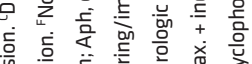

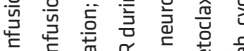

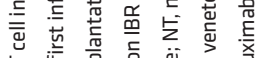

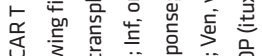

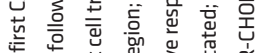

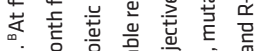

结要

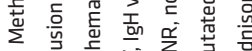

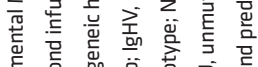

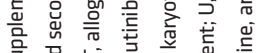

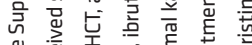

ํㅡㄴ

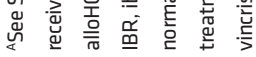


Table 2. Demographic and clinical characteristics of treated patients with R/R B-NHL and outcomes

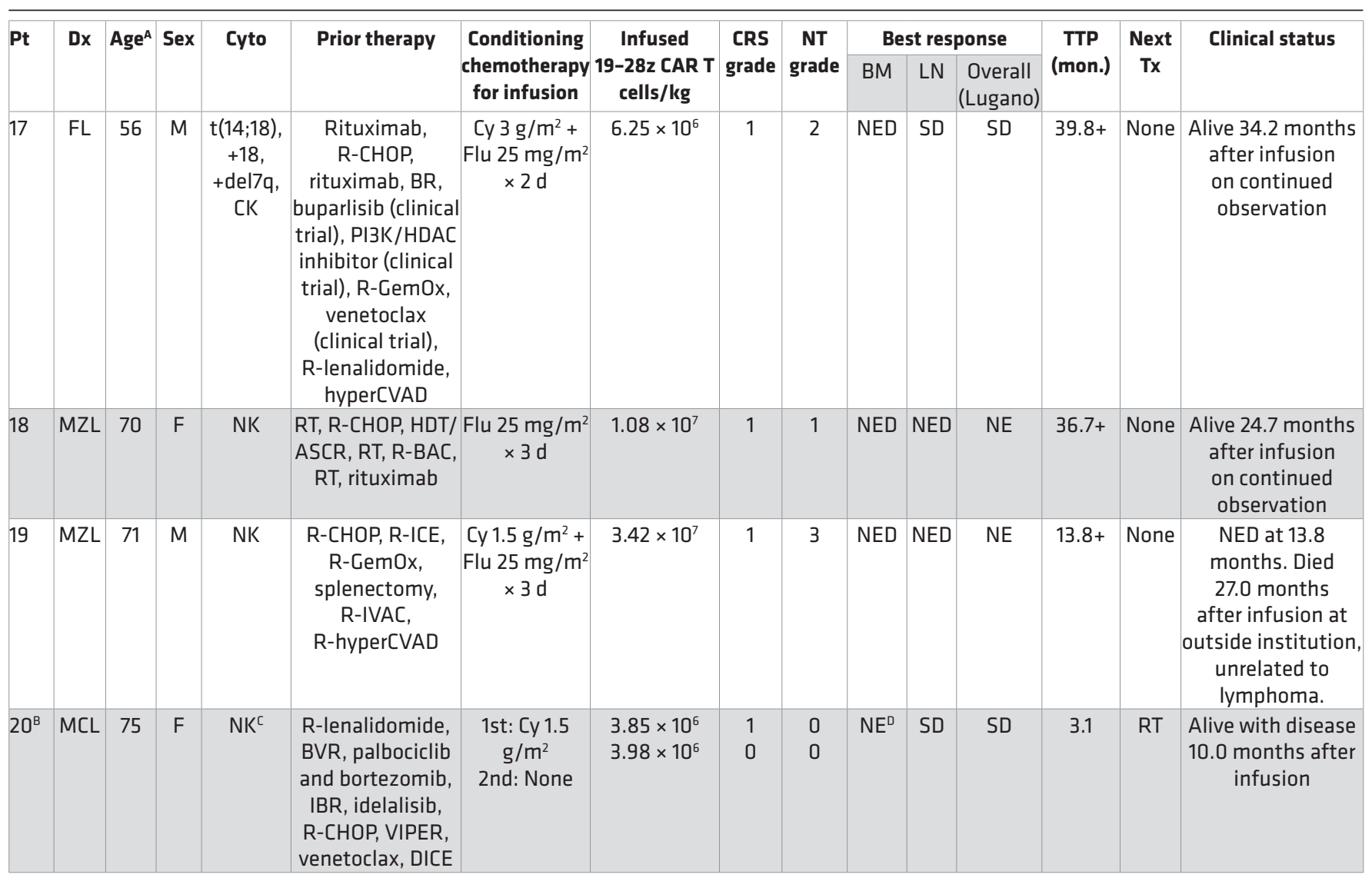

${ }^{A}$ At first CAR T cell infusion. ${ }^{B}$ Received multiple CAR T cell infusions. ' No cytogenetic abnormalities documented, though Cyclin D1 overexpression confirmed. ${ }^{\circ} \mathrm{BM}$ not evaluated immediately following CAR T cell infusion, as had no evidence of BM involvement prior to CAR T cell infusion but developed eventual progression in BM concurrent with progression at other sites. CK, complex karyotype; Cy, cyclophosphamide; Cyto, notable cytogenetic features; Dx, diagnosis; FL, follicular lymphoma; Flu, fludarabine; HDT/ASCT, high-dose chemotherapy with autologous stem cell rescue; IBR, ibrutinib; MCL, mantle cell lymphoma; MZL, marginal zone lymphoma; NE, not evaluable; NED, No evidence of disease prior to or following CAR T cell infusion; NK, normal karyotype; PI3K/HDAC, phosphoinositide 3-kinase/histone deacetylase; Pt, patient reference number; R, rituximab; RT, radiation therapy; SD, stable disease. Chemotherapy regimens included BR (bendamustine and rituximab); BVR (bendamustine, bortezomib, and rituximab); DICE (dexamethasone, ifosfamide, cisplatin, and etoposide); hyperCVAD (hyperfractionated cyclophosphamide, vincristine, doxorubicin, and dexamethasone); R-BAC (rituximab, bendamustine, and cytarabine); R-CHOP (rituximab, cyclophosphamide, doxorubicin, vincristine, and prednisone); R-GemOx (rituximab, gemcitabine, and oxaliplatin); R-ICE (rituximab, ifosfamide, cisplatin, and etoposide); R-IVAC (rituximab, ifosfamide, etoposide, and cytarabine); VIPER (bortezomib, ifosfamide, cisplatin, etoposide, and rituximab).

The median absolute lymphocyte counts (ALCs) on the first day of CAR T cell infusion were 4.4, 0.9, and $0.1 \mathrm{~K} / \mu \mathrm{l}$ among patients with CLL receiving cyclophosphamide (Cy), bendamustine, or Flu/Cy conditioning, respectively (Supplemental Figure 2).

CAR $T$ cell product manufacturing. Autologous $\mathrm{T}$ cell collection was performed at a median of 38 days (range, 20-225 days) and 109 days (range, 68-139 days) prior to CAR T cell infusion in patients with CLL and B-NHL, respectively; median ALC at the time of leukapheresis was, respectively, $4.3 \mathrm{~K} / \mu 1$ (range, $0.3-169.9 \mathrm{~K} / \mu \mathrm{l}$ ) and $0.4 \mathrm{~K} / \mu 1$ (range, $0.1-2.4 \mathrm{~K} / \mu \mathrm{l}$ ). In the $\mathrm{CLL}$ cohort, the median $\mathrm{CD}^{+} / \mathrm{CD}^{+}$ratio in the collected autologous T cells was 1.9:1 (range, 0.3:1-4.5:1) and in the infused 19-28z CAR T cell products was 5.7:1 (range, 0.3:1-118.0:1). In the B-NHL cohort, the median CD4 ${ }^{+} / \mathrm{CD}^{+}$ratio in the collected autologous T cells was 1.9:1 (range, 0.9:1-13.2:1) and in the infused 19-28z CAR T cell products was 1.8:1 (range, 0.8:1-3.1:1). Median transduction efficiency was 30\% (range, 22\%-59\%), and median CAR T cell product manufacturing time was 15 days (range, 11-19 days) for the entire cohort.

Cumulative expansion of autologous $\mathrm{T}$ cells ex vivo, from day 3 to day 11, was significantly greater for the 4 patients on ibrutinib at time of leukapheresis versus the 11 ibrutinib-naive patients at the time of 
50 patients signed

informed consent for

the clinical study

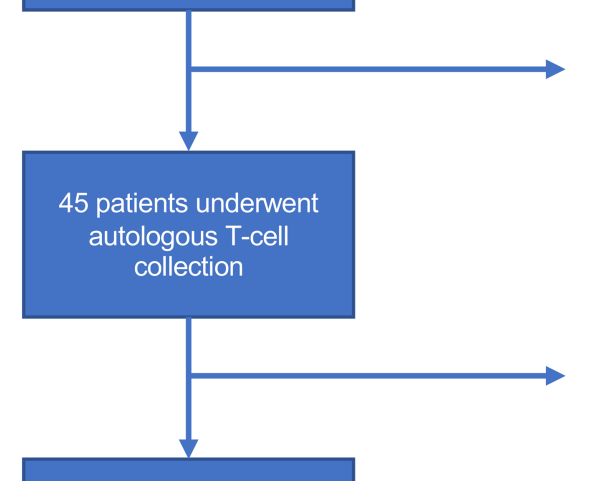

$\underline{5 \text { patients never underwent } \mathrm{T} \text {-cell collection }}$

-Chose to continue care outside our institution $(n=3)$

-Began or continued alternative therapy $(n=2)$

CAR T-cell products

manufactured per

protocol for 37 patients
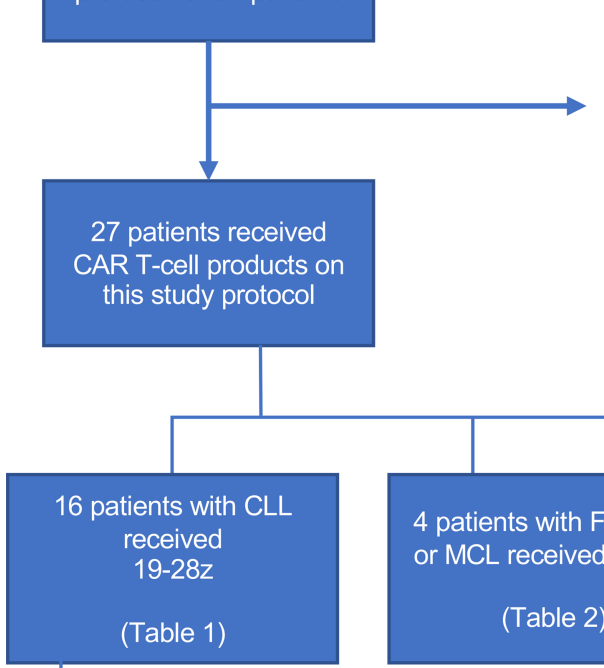

CAR T-cell products not manufactured on this protocol for 8 patients

-Began or continued alternative therapy $(n=6)$

-Autologous T-cells collected on this protocol used to

manufacture CAR T-cell product for alternative clinical trial $(n=2)$

$\underline{\text { CAR T-cell products not infused on this protocol in } 10 \text { patients }}$

-Began or continued alternative therapy $(n=6)$

-Died awaiting CAR T-cell therapy $(n=3)$

-Resumed observation $(n=1)$

received

AR T-cell products on

this study protocol
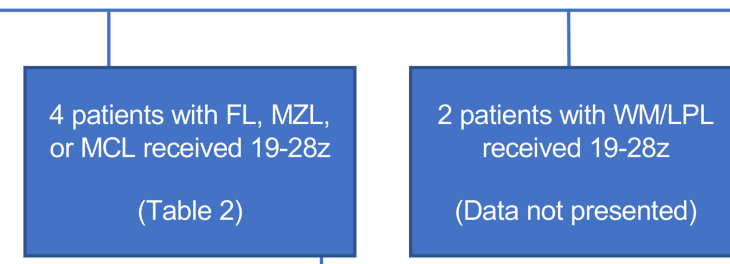

(Data not presented)

5 patients with CLL

received $19-28 z+$

another cellular therapy

(Data not presented)
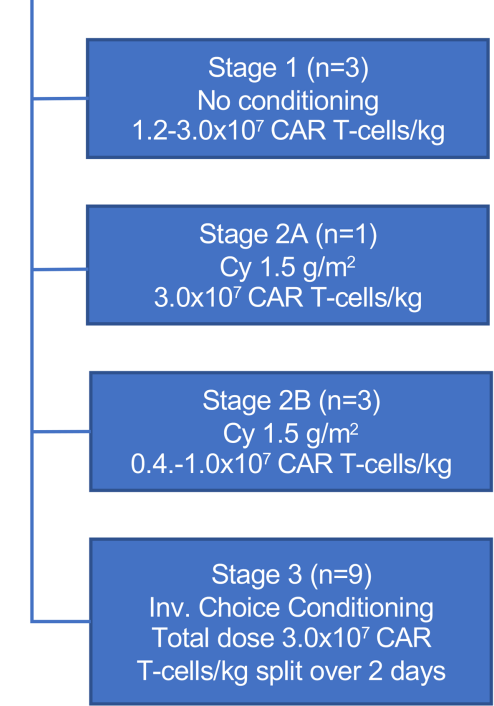

\section{Stage $3(n=4)$}

Inv. Choice Conditioning

Total dose $3.0 \times 10^{7}$ CAR

T-cells/kg split over 2 days

Figure 1. Enrollment of patients in the clinical study. Status of enrolled patients and schematic of study stages on which patients were treated. 19-28z, 19-28z CAR T cells; Cy, cyclophosphamide; Inv. Choice, investigator's choice; WM/LPL, Waldenstrom macroglobulinemia/lymphoplasmacytic lymphoma 


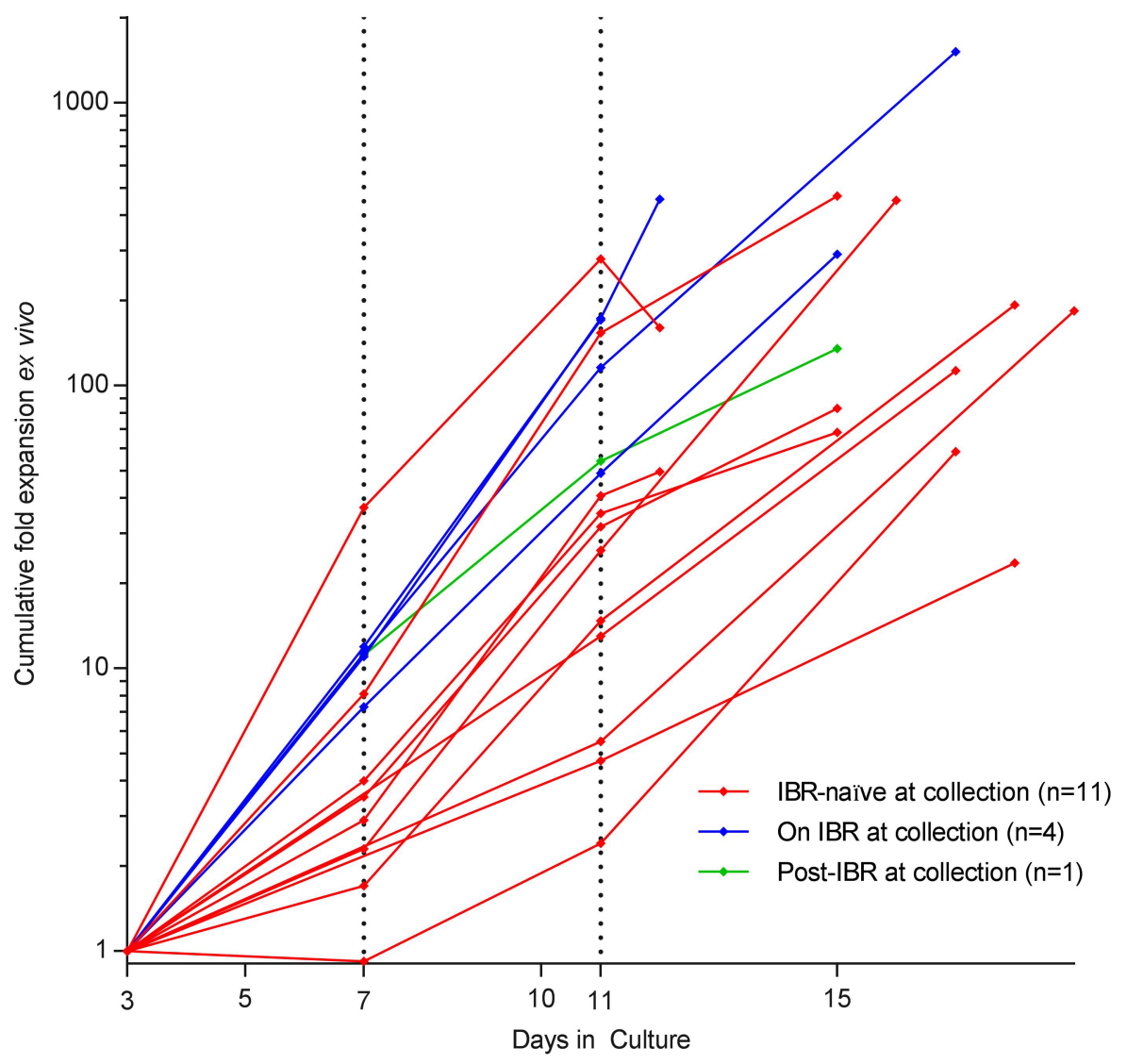

Figure 2. Kinetics of ex vivo T cell expansion. Cumulative fold $T$ cell expansion ex vivo is depicted for patients with CLL on ibrutinib (IBR) at the time of leukapheresis (blue lines) versus IBR-naive patients (red lines) versus patients previously on ibrutinib (green line). Note log scale.

leukapheresis (median 143.3-fold vs. 26.1-fold, $P=0.040$ ) and approached significance at the end of production (EOP) (median 373.9-fold vs. 112.7-fold, $P=0.056$ ) (Figure 2). The median manufacturing times for the 2 cohorts were similar (13.5 vs. 16 days).

Immunophenotypic characteristics of EOP T cells in CLL patients are summarized in Table 3. Compared with those in ibrutinib-naive patients, EOP $\mathrm{T}$ cells in patients undergoing leukapheresis while on ibrutinib demonstrated a higher fraction of $\mathrm{CD}^{+} \mathrm{CAR}^{+} \mathrm{T}$ cells with a CD62 $\mathrm{L}^{+} \mathrm{CD} 127^{+}$(central memory [Tcm]) phenotype (median $29.0 \%$ vs. $1.9 \%, P=0.047$ ), a higher fraction of $\mathrm{CD}^{+} \mathrm{CAR}^{+} \mathrm{T}$ cells with a $\mathrm{CD}_{2} \mathrm{~L}^{+} \mathrm{CD} 127^{+}$phenotype (median $58.4 \%$ vs. $5.6 \%, P=0.0061$ ), and a lower fraction of $\mathrm{CD}^{2} 2 \mathrm{~L}^{-} \mathrm{T}$ cells (effector/effector memory phenotype) across $\mathrm{CD}^{+} \mathrm{CAR}^{+}$(median $12.8 \%$ vs. $50.4 \%, P=0.11$ ) and $\mathrm{CD} 4^{+}$ $\mathrm{CAR}^{+}$(median $18.9 \%$ vs. $63.1 \%, P=0.024$ ) $\mathrm{T}$ cell subsets. Of note, the fraction of CAR T cells with an alternative $\mathrm{Tcm}$ phenotype $\left(\mathrm{CCR} 7^{+} \mathrm{CD} 45 \mathrm{RA}{ }^{-}\right)$was small in most patients, though nonsignificantly greater proportions of $\mathrm{CD}^{+} \mathrm{CAR}^{+} \mathrm{T}$ cells with $\mathrm{CCR} 7^{+} \mathrm{CD} 45 \mathrm{RA}^{-}$phenotype (median 1.2 vs. $0.1 \%$ ) and $\mathrm{CD}^{+}$ $\mathrm{CAR}^{+} \mathrm{T}$ cells with $\mathrm{CCR} 7^{+} \mathrm{CD} 45 \mathrm{RA}^{-}$phenotype (median $1.4 \%$ vs. $0.5 \%$ ) were observed among patients undergoing leukapheresis while on ibrutinib (vs. ibrutinib naive).

Safety and toxicity. CRS was observed in all patients in this analysis. Due to early development of CRS, the second fraction of CAR T cells was withheld in 6 of 11 patients with CLL for whom split-dose CAR T cell infusion had been planned (patients 5-15, see Methods), including in 4 of 5 patients on ibrutinib at the time of or immediately prior to CAR T cell infusion. Maximal CRS severity was most commonly grade $1(n=8)$ or grade $2(n=10) ; 1$ patient developed grade 3 CRS (see Tables 1 and 2 ). Patient 4 developed persistent fever, hypotension, and renal failure and died within 48 hours of 19-28z CAR T cell infusion in the setting of a suspected sepsis syndrome, as we have previously reported; however, because of etiologic uncertainty, this patient is classified as having developed grade 5 CRS (27). The duration, severity, and treatment of CRS were recorded for each day of inpatient hospitalization following CAR T cell infusion (Supplemental Figure 3); for all infusions complicated by CRS of any grade, the median onset was at day 1 (the day of infusion) and the latest onset was at day 3 . CRS had a median duration of 2 days (range, 1-9 days). Three patients received the IL- 6 receptor-directed monoclonal antibody tocilizumab for CRS management. In the 5 patients receiving ibrutinib concurrent with 
Table 3. T cell memory subset immunophenotyping of end-of-production CAR T cells in patients with CLL

\begin{tabular}{|c|c|c|c|c|c|c|c|c|c|c|c|c|c|}
\hline & \multirow{3}{*}{$\begin{array}{l}\text { Staining panel } \\
\text { Subgroups } \\
\text { (mean \%) }\end{array}$} & \multicolumn{4}{|c|}{ CCR7, CD45RA } & \multicolumn{4}{|c|}{ CD62L, CD127 } & \multicolumn{4}{|c|}{ CD27, CD28 } \\
\hline & & $\mathrm{CCR}^{-}$ & $\mathrm{CCR}^{+}$ & $\mathrm{CCR7}^{+}$ & CCR7 $^{-}$ & $\mathrm{CD} 2 \mathrm{~L}^{+}$ & $\mathrm{CD} 6 \mathrm{~L}^{+}$ & $\mathrm{CD} 6 \mathrm{~L}^{-}$ & $\mathrm{CD}^{2} \mathrm{~L}^{-}$ & $\mathrm{CD}^{2} 7^{+}$ & $\mathrm{CD} 27^{+}$ & $\mathrm{CD}_{27}^{-}$ & $\mathrm{CD}^{-} 7^{-}$ \\
\hline & & $\mathrm{CD} 45 \mathrm{RA}^{+}$ & $\mathrm{CD} 45 \mathrm{RA}^{+}$ & $\mathrm{CD}^{\mathrm{C}} \mathrm{R} \mathrm{RA}^{-}$ & CD45RA $^{-}$ & CD127- & $\mathrm{CD} 127^{+}$ & $\mathrm{CD} 127^{+}$ & CD127- & CD28- & CD28+ & $\mathrm{CD}^{\circ} 8^{+}$ & $\mathrm{CD}^{-} 8^{-}$ \\
\hline \multirow{2}{*}{$\begin{array}{l}\text { On IBR at } \\
\text { apheresis }(n=4)\end{array}$} & $\mathrm{CD}^{+} \mathrm{CAR}^{+}$Gate & 73.4 & 10.1 & 1.6 & 15.2 & 45.0 & 29.0 & 2.7 & 23.3 & 2.4 & 36.5 & 37.9 & 23.2 \\
\hline & $\mathrm{CD8}^{-}$CAR $^{+}$gate & 37.7 & 2.6 & 1.5 & 58.2 & 25.3 & 50.7 & 14.4 & 9.6 & 0.2 & 29.3 & 67.5 & 3.1 \\
\hline \multirow{2}{*}{$\begin{array}{l}\text { Evaluable IBR- } \\
\text { naive patients at } \\
\text { apheresis }^{A}(n=7)\end{array}$} & $\mathrm{CDB}^{+} \mathrm{CAR}^{+}$gate & 82.6 & 10.9 & 0.4 & 6.0 & 41.3 & 4.3 & 1.2 & 53.2 & 16.4 & 30.0 & 31.0 & 22.6 \\
\hline & $\mathrm{CD8}^{-} \mathrm{CAR}^{+}$gate & 57.4 & 4.4 & 1.1 & 37.0 & 36.3 & 5.9 & 6.9 & 50.9 & 1.6 & 14.4 & 74.4 & 9.6 \\
\hline \multirow{2}{*}{$\begin{array}{l}\text { All evaluable } \\
\text { patients }(n=12)^{\mathrm{B}}\end{array}$} & $\mathrm{CD}^{+} \mathrm{CAR}^{+}$gate & 80.7 & 10.0 & 0.8 & 8.6 & 42.6 & 13.7 & 2.1 & 41.7 & 10.5 & 31.8 & 33.9 & 23.8 \\
\hline & $\mathrm{CD8}^{-} \mathrm{CAR}^{+}$gate & 51.3 & 3.8 & 1.3 & 43.5 & 32.0 & 23.8 & 10.3 & 33.9 & 1.0 & 20.3 & 71.5 & 7.2 \\
\hline
\end{tabular}

${ }^{A}$ Excludes the first 4 patients accrued, whose enrollment predated the staining panels used above. ${ }^{B}$ Includes the patient who had progressed on IBR and was off IBR for 19 months prior to autologous T cell collection. IBR, ibrutinib.

or immediately prior to CAR T cell infusion, maximal severity of CRS was grade $\geq 2$ in 3 patients, 2 of whom required vasopressors and received tocilizumab; both had additionally received Flu-containing conditioning chemotherapy.

Six CLL and three B-NHL patients developed one or more neurologic adverse events (AEs), excluding isolated headache; two of these patients received corticosteroids (see Tables 1 and 2). The duration, severity, and treatment of neurologic toxicity are summarized for individual patients (Supplemental Figure 4); for all infusions complicated by neurologic toxicity of any grade, the median onset was at day 2 and the latest onset was at day 11. Neurologic toxicity had a median duration of 1 day (range, 1-61 days). Two patients (patients 13 and 19) developed reversible grade 3 encephalopathy; patient 19 experienced prolonged encephalopathy and dysphasia, with gradual improvement to baseline (Supplemental Figure 4). All other neurologic AEs, which comprised encephalopathy $(n=5)$, dysphasia $(n=3)$, dysarthria $(n=1)$, and hallucinations $(n=1)$, were grade 1 or 2 and were similarly reversible. Four of the five CLL patients receiving concurrent ibrutinib (including patient 13) experienced neurologic AEs; of note, one of these patients (patient 15) experienced no neurologic AEs following initial CAR T cell infusion but developed grade 2 dysphasia following a second infusion 1 month thereafter. Grade 3 or 4 AEs other than CRS and neurologic toxicity considered definitely, probably, or possibly related to protocol therapy are summarized in Table 4.

Survival and clinical responses. Among the 16 treated patients with CLL, the median follow-up for survivors was 40.6 months (range 1.8-79.8 months), median event-free survival (EFS) was 3.1 months, and median overall survival was 17.1 months; in the 4 patients with B-NHL, median EFS was 33.4 months, and median overall survival was not reached (Figure 3). Clinical responses are summarized in Tables 1 and 2. Objective responses were observed in 6 of 16 CLL patients (38\%) - comprising 50\% of the $12 \mathrm{CLL}$ patients who had received conditioning chemotherapy and were considered evaluable, and 4 of the 5 patients (80\%) receiving concurrent ibrutinib. Three of these twelve CLL patients (evaluable, received conditioning chemotherapy; 25\%) achieved CR by International Workshop on Chronic Lymphocytic Leukemia (IWCLL) criteria; 2 had MRD-negative responses by flow cytometry and deep sequencing for the malignant clonal IgH rearrangement. Three additional CLL patients in this group $(25 \%)$ achieved CR $(n=1)$ or partial response $(\mathrm{PR})(n=2)$ in the BM and a best overall response of stable disease (SD) by IWCLL criteria.

Patients receiving ibrutinib resumed it after CAR T cell infusion (Supplemental Table 5). Of the 3 CLL patients who achieved CR, 2 were on ibrutinib at leukapheresis and CAR T cell infusion. One patient achieved MRD-positive CR following CAR T cell infusion (patient 12) and remains in CR on ibrutinib maintenance; in the others exposed to ibrutinib, it was ultimately continued until last follow-up (patient 11), discontinued 13 months after infusion (in patient 13, who achieved MRD-negative CR and retained that status off all CLL-directed therapy at $>40$ months after infusion), continued concomitant with R-CHOP after Richter syndrome developed (patient 14), and discontinued on progression (patient 15).

Of the 3 CLL patients who achieved CR, none have experienced relapse. One of the two who achieved MRD-negative CR never received ibrutinib and has remained off all CLL-directed therapy and had no evidence of disease for $>6$ years after infusion. Of the 12 evaluable CLL patients who did not achieve CR, 1 
Table 4. Numbers of patients with grade 3-5 adverse events definitely, probably, or possibly related to protocol therapy, as assessed by CTCAE v4.0, other than cytokine release syndrome

\begin{tabular}{|c|c|c|c|c|}
\hline Toxicity & Total Grade 3-5 & Grade 3 & Grade 4 & Grade $5^{A}$ \\
\hline Neutropenia & 8 & 2 & 6 & 0 \\
\hline Anemia & 6 & 1 & 0 & 0 \\
\hline Thrombocytopenia & 5 & 2 & 3 & 0 \\
\hline Hypophosphatemia & 5 & 5 & 0 & 0 \\
\hline Lymphopenia & 4 & 0 & 4 & 0 \\
\hline Hyperglycemia & 4 & 4 & 0 & 0 \\
\hline Hyponatremia & 4 & 4 & 0 & 0 \\
\hline Hypocalcemia & 3 & 3 & 0 & 0 \\
\hline Tumor lysis syndrome & 2 & 1 & 0 & 1 \\
\hline Hyperkalemia & 2 & 1 & 1 & 0 \\
\hline ALT increased & 1 & 1 & 0 & 0 \\
\hline $\begin{array}{l}\text { Alkaline phosphatase } \\
\text { increased }\end{array}$ & 1 & 1 & 0 & 0 \\
\hline Blood bilirubin increased & 1 & 1 & 0 & 0 \\
\hline Encephalopathy & 1 & 1 & 0 & 0 \\
\hline Enterocolitis & 1 & 1 & 0 & 0 \\
\hline Fatigue & 1 & 1 & 0 & 0 \\
\hline Fibrinogen decreased & 1 & 1 & 0 & 0 \\
\hline Hypokalemia & 1 & 1 & 0 & 0 \\
\hline
\end{tabular}

was lost to follow-up and 11 patients in active follow-up at MSK have either died as a result of progressive CLL $(n=8)$ or received alternative treatment (ibrutinib, $n=1$; allogeneic hematopoietic stem cell transplantation, $n=1$; other investigational therapy, $n=1$ ) and remain alive in active follow-up (see Table 1 ). The rate of EFS did not differ significantly between patients with CLL who attained BM response only (with SD per IWCLL criteria) or had no response. Two patients with B-NHL (50\%) were in CR at the time of T cell infusion and maintained CR, while 2 exhibited SD (see Table 2).

CAR $T$ cell retreatment. Three patients with CLL and one patient with mantle cell lymphoma were retreated with 19-28z CAR T cells following initial nonresponse (see Tables 1 and 2). Two patients with CLL developed CRS and neurologic toxicity of grade $\leq 2$ following CAR $T$ cell reinfusion; in both cases, CAR T cells were detectable in peripheral blood (PB) by quantitative PCR (qPCR) following reinfusion (Figure 4A). Additionally, in these 2 patients, reduction in BM infiltration by CLL (PR, $n=1$; MRD-positive CR, $n=1$ ) was observed following second, but not first, CAR T cell infusion. In the other 2 retreated patients, CAR T cells were not detectable after reinfusion and the best response of SD was observed following reinfusion.

CAR T cell expansion and persistence. Peak expansion of 19-28z CAR T cells in PB was observed 7-14 days following initial or subsequent CAR T cell infusion (Figure 4). The 2 patients achieving MRD-negative CR exhibited significantly greater peak CAR T cell expansion in PB by qPCR $(P=0.011)$ and FACS $(P$ $=0.00057)$ compared with all other patients. Although patient 12 achieved MRD-positive CR, CAR T cells were not detectable after infusion by qPCR or FACS. The CLL patients receiving Flu-containing conditioning regimens (patients 13-15) achieved the lowest ALC at the time of CAR T cell infusion (see Supplemental Figure 2) and significantly greater peak CAR T cell expansion in PB by qPCR $(P=0.0077$; see Figure 4) compared with patients with CLL who did not receive Flu during conditioning. In 2 patients, CAR T 


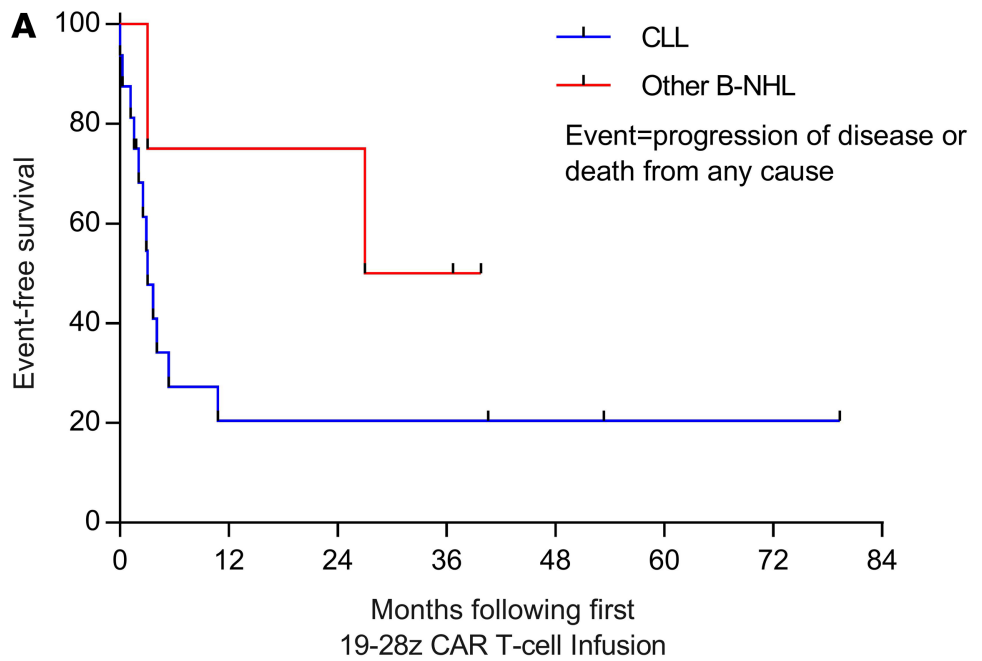

Figure 3. Survival outcomes. EFS (A) and OS (B) are depicted for patients with CLL (blue lines) and patients with other B-NHL (red lines), measured from the time of first $19-28 z$ CAR T cell infusion, using the Kaplan-Meier method. B-NHL, B cell non-Hodgkin lymphoma; CLL, chronic lymphocytic leukemia; EFS, event-free survival; OS, overall survival.

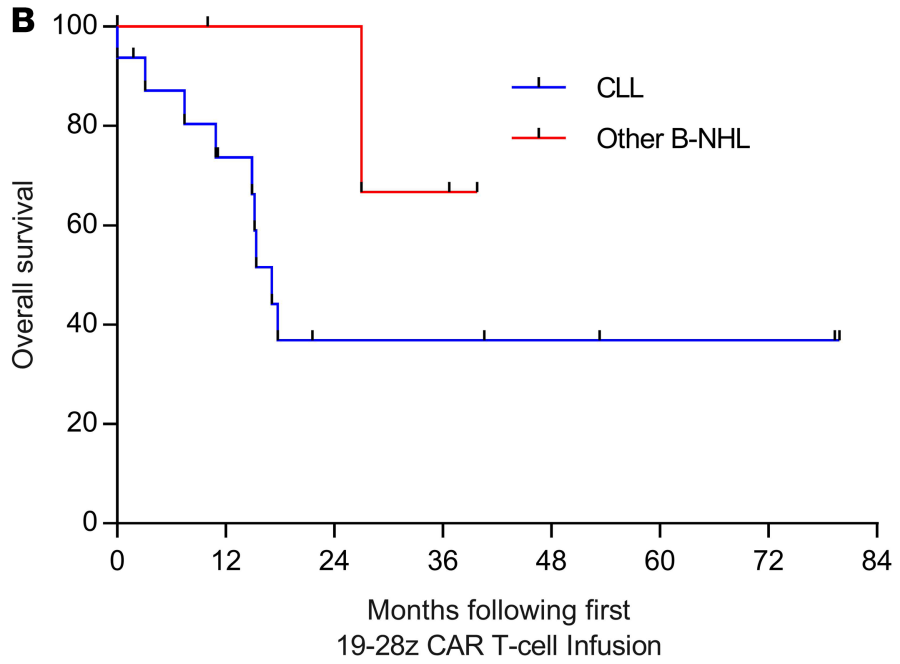

cells were detectable by qPCR in BM but not PB. In 2 further patients, PB CAR T cells were detectable by qPCR following brief in vitro expansion, as previously described (16). The maximal detectable CAR T cell persistence in $\mathrm{PB}$ was 21 days.

Cytokine levels. To assess the effects of ibrutinib exposure on immunoregulatory cytokine production, we examined maximal fold increases in selected cytokines following CAR T cell infusion among 10 evaluable CLL patients who received conditioning chemotherapy (Figure 5), stratified by those who were ibrutinib naive at the time of CAR T cell infusion $(n=5)$ compared with those on ibrutinib during or immediately prior to CAR T cell infusion $(n=5)$ (see Supplemental Table 5 for ibrutinib exposure at time of CAR $\mathrm{T}$ cell infusion). There were significantly higher fold increases in the levels of IL-6 (median 57.6-fold vs. 13.0-fold, $P=0.01$ ) and IL-10 (median 72.0-fold vs. 4.7-fold, $P=0.02$ ) in ibrutinib-exposed compared with ibrutinib-naive patients, respectively, and a nonsignificant similar trend in IFN- $\gamma$ levels (median 52.0-fold vs. 5.3-fold, $P=0.10$ ). Trends in cytokine levels for individual patients before, during, and following CAR $\mathrm{T}$ cell infusion are shown for selected cytokines in Supplemental Figure 5. Patients 1-3 did not receive conditioning chemotherapy, patient 4 was nonevaluable as previously described, and cytokine samples were not available for patient 8 . Patient 16 , who had prior ibrutinib exposure but had experienced progression of disease, is not included in the fold-change analysis; her cytokine levels following her first 2 CAR T cell infusions are depicted along with others in Supplemental Figure 5.

\section{Discussion}

This phase I trial demonstrates the safety and feasibility of $19-28 \mathrm{z}$ CAR $\mathrm{T}$ cell therapy in patients with $\mathrm{R} / \mathrm{R}$ CLL and indolent B-NHL, including in the setting of ongoing therapy with ibrutinib. Despite CAR $\mathrm{T}$ cell doses of up to $3 \times 10^{7} / \mathrm{kg}$ (10-fold higher than the maximum tolerated dose of $19-28 \mathrm{z}$ CAR T cells 


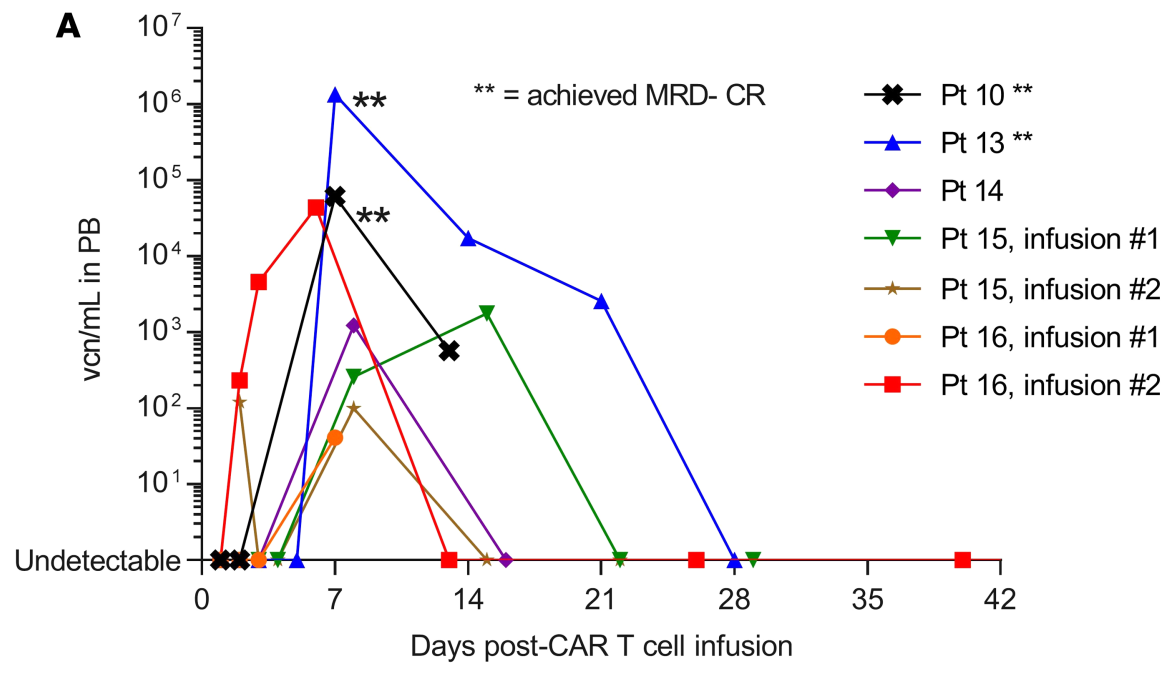

Figure 4. CAR T cell expansion in vivo. (A) 19-28z CAR T cell expansion, measured in vector copy numbers per $\mathrm{ml}(\mathrm{vcn} / \mathrm{ml})$ in peripheral blood among patients with CLL with quantifiable CAR T cell expansion after infusion. (B) 19-28z CAR T cell expansion by FACS (CAR+ ${ }^{+}$cells $\left./ \mathrm{ml}\right)$ in the 2 patients achieving MRD-negative CR. Note log scale. The 2 patients achieving MRD-negative $\mathrm{CR}\left({ }^{* *}\right)$ exhibited significantly greater peak CAR T cell expansion in PB by qPCR $(P=0.011)$ and FACS $(P=0.00057)$ compared with all other patients (Wilcoxon-Mann-Whitney test). CLL, chronic lymphocytic leukemia; CR, complete response; $\mathrm{MRD}$, minimal residual disease; $\mathrm{PB}$, peripheral blood; qPCR, quantitative PCR.

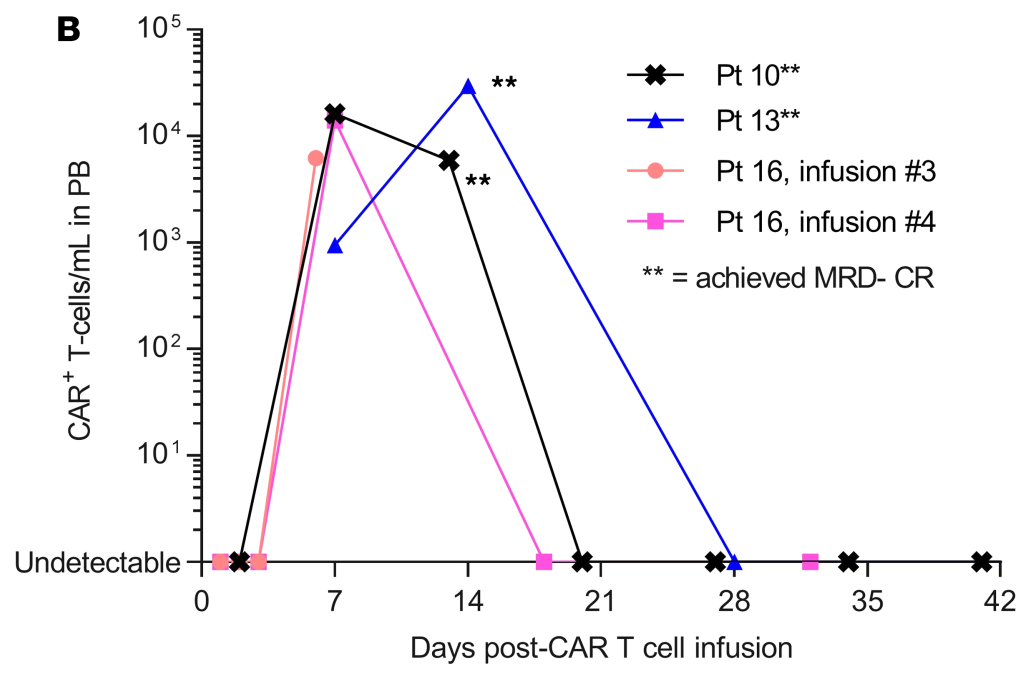

in patients with $\mathrm{B}-\mathrm{ALL}$ ), rates of grade $\geq 3 \mathrm{CRS}$ and neurologic toxicity were only $10 \%$, though all patients developed CRS, and transient grade 1-2 neurologic toxicities were not uncommon (35\%). Observed rates of CR among patients receiving conditioning chemotherapy prior to 19-28z CAR T cell infusion were similar to those reported by mature series investigating CD19-targeted CAR T cell therapies in patients with R/R CLL $(12-14,17,18)$. An additional subgroup experienced considerable reduction in BM involvement without achieving objective response by IWCLL criteria, because of persistent nodal involvement; others have also reported apparent greater sensitivity of BM-based compared with lymph node-based CLL to CD19-targeted CAR T cells (17). In this series, which had a median follow-up of 40.6 months (range, 1.8-79.8 months), relapse was not observed in the patients achieving $\mathrm{CR}$, similar to the findings reported by Porter and colleagues (14). Two patients achieved MRD-negative CR by flow cytometry and IgH deep sequencing and had ongoing CR at last follow-up ( $>6$ years in 1 patient). The 2 CLL patients achieving MRD-negative CR exhibited the most robust CAR T cell expansion, consistent with other series $(14,17)$. The length of follow-up herein further confirms that such responses may be sustained despite limited persistence of $19-28 z$ CAR T cells.

Several series have reported greater CAR T cell expansion in patients with R/R B-ALL or B-NHL who receive Flu as part of conditioning chemotherapy $(18,21,24,28)$. Our data further suggest that ibrutinib therapy concurrent with leukapheresis and CAR T cell infusion may promote $\mathrm{T}$ cell expansion ex vivo and alter CAR T cell memory phenotypes, though the very small numbers of ibrutinib-naive versus ibrutinib-exposed patients herein limits firm conclusions, and our findings are best considered exploratory and hypothesis generating. Ibrutinib may also debulk lymph nodes, which appear to be less sensitive to current CAR 


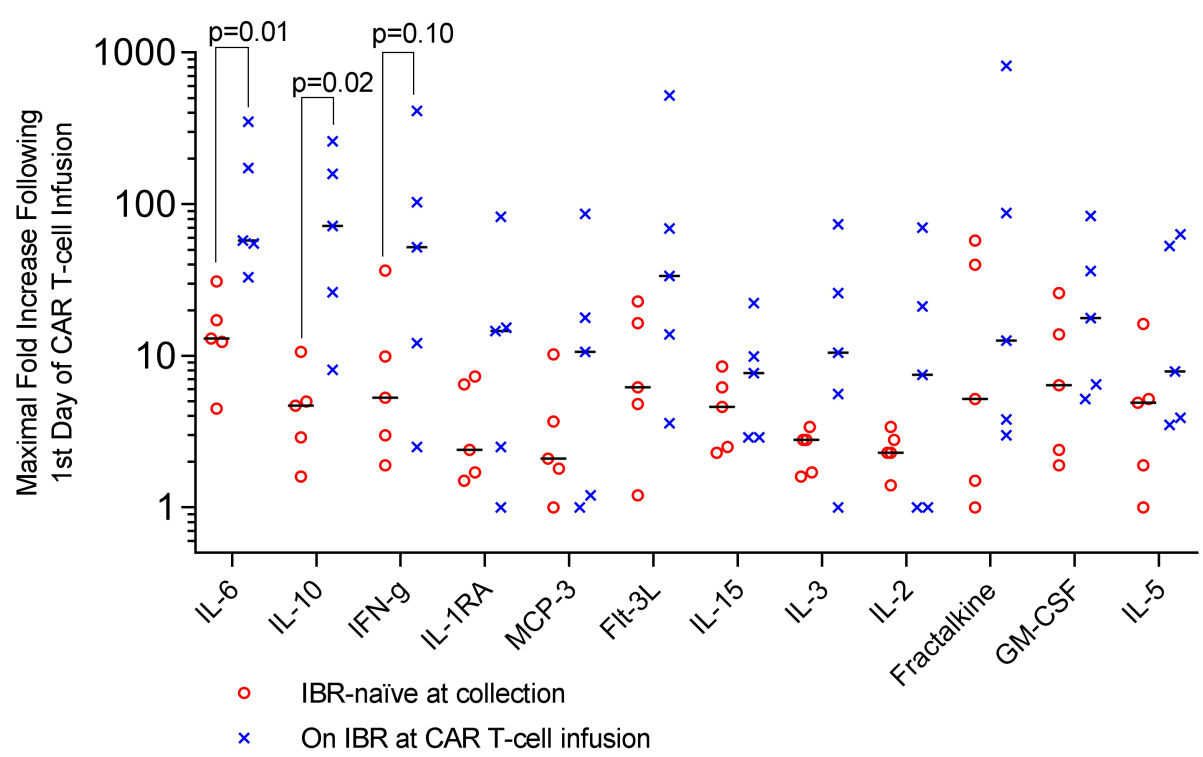

Figure 5. Peak levels of immunoregulatory cytokines following CAR T cell infusion. Dot plots depicting fold increase in cytokine levels from prior to the first day of CAR T cell infusion to the peak within 1 month of infusion in 10 evaluable patients with CLL who received conditioning chemotherapy and CAR T cell infusion, stratified by whether ibrutinib naive ( $n=5$, open red circles) or on ibrutinib (IBR) at or immediately prior to CAR T cell infusion ( $n=5$, blue "X" marks). Median fold changes for each group are marked with black bars. Patients with ongoing or recent ibrutinib exposure at the time of CAR T cell infusion exhibited a significantly greater median fold increase in IL-6 and IL-10 (Wilcoxon-Mann-Whitney test). CLL, chronic lymphocytic leukemia. Note log scale.

$\mathrm{T}$ cell therapies, prior to infusion. Autologous $\mathrm{T}$ cells in patients with CLL exhibit impairments in ex vivo expansion compared with T cells from patients with ALL (29). CLL cells additionally interfere with T cell effector function and induce $\mathrm{T}$ cell exhaustion (30-33). Off-target effects of ibrutinib may alter $\mathrm{T}$ cell phenotypes via inhibition of IL-2-inducible $\mathrm{T}$ cell kinase (ITK), which may skew $\mathrm{CD} 4^{+} \mathrm{T}$ cell subsets from $\mathrm{Th} 2$ toward Th1 bias and thereby enhance antitumor immune responses independent of BTK inhibition (34). Fraietta et al. previously reported that $\mathrm{T}$ cells from CLL patients receiving ibrutinib for $\geq 5$ months recovered near-normal proliferative capacity, exhibited decreased expression of PD-1 and CD200, improved ex vivo expansion after transduction with a 4-1BB-containing second-generation CD19-targeted CAR (CTL019), and enhanced CTL019 expansion and murine survival in xenograft models bearing Nalm6 and OSU-CLL tumors (29). In this report, CAR T cells derived from the 4 patients receiving ongoing ibrutinib treatment at leukapheresis exhibited significantly $(P=0.040)$ greater ex vivo expansion by day 11 and a significantly $(P$ $=0.047)$ greater fraction of $\mathrm{CD} 8^{+} \mathrm{CAR}^{+} \mathrm{T}$ cells with $\mathrm{Tcm}$ phenotype, as defined by coexpression of $\mathrm{CD} 62 \mathrm{~L}$ and $\mathrm{CD} 127$ (35). Of note, a smaller proportion of CAR T cells exhibited the classic CCR $7^{+} \mathrm{CD} 45 \mathrm{RA}^{-} \mathrm{Tcm}$ phenotype. While CD62L and CCR7 both serve in trafficking of lymphocytes to secondary lymphoid organs, and several groups have utilized CD62L in lieu of CCR7 to designate Tcm subsets $(36,37)$, discrepancies in CD62L and CCR7 expression have been observed by others $(38,39)$, and further studies would be required to determine whether $\mathrm{CD} 8{ }^{+} \mathrm{CD} 62 \mathrm{~L}^{+} \mathrm{CD} 127^{+} \mathrm{CAR} \mathrm{T}$ cells functionally recapitulate the $\mathrm{Tcm}$ phenotype in this context, independent of CCR7 expression. Others have previously reported that CD8 $8^{+} \mathrm{CAR}$ $\mathrm{T}$ cells with a Tcm phenotype appear to demonstrate the greatest direct antitumor potency as single subset in NOD $/ \mathrm{SCID} / \gamma \mathrm{C}^{-/-}$mice bearing Raji tumors (40). A recent report also noted a greater portion of $\mathrm{CD} 8{ }^{+} \mathrm{C}$ $\mathrm{D}^{2} 5 \mathrm{RO}^{-} \mathrm{CD} 27^{+} \mathrm{T}$ cells at leukapheresis in patients with CLL achieving CR compared with those achieving $\mathrm{PR} /$ nonresponse following CTL019 infusion (41). CAR T cell populations herein demonstrated a notable skew toward $\mathrm{CD} 4^{+}$versus $\mathrm{CD} 8^{+}$as the dominant population, particularly among the patients with CLL, as observed in other studies (15). In this small series, neither CD4/CD8 ratio at leukapheresis nor proportion of infused $\mathrm{CD} 27^{+} \mathrm{CD} 8^{+} \mathrm{CAR}^{+} \mathrm{T}$ cells was associated with ibrutinib exposure or predictive of $\mathrm{CR}$ (data not shown), though ibrutinib exposure was associated with differences in $\mathrm{T}$ cell phenotype as described above. Additionally, patients on ibrutinib at the time of CAR T cell infusion exhibited a significantly greater fold increase in IL-6 and IL-10 levels and a trend toward greater fold increase in IFN- $\gamma$ levels, compared with ibrutinib-naive patients, further suggesting that ibrutinib exposure may have altered the phenotype of the 
infused CAR T cell product, although Flu-containing conditioning in 3 of 5 patients may also have modulated CAR T cell expansion in vivo and enhanced cytokine production.

Gill et al. (42) and Gauthier et al. (43) have recently reported high rates of response in patients with R/R CLL treated with ibrutinib followed by CTL119 or JCAR014, respectively, which are both CD19-targeted lentiviral-transduced autologous $\mathrm{T}$ cell products with a 4-1BB costimulatory domain. The majority of patients in both series achieved MRD negativity in the BM by FACS. Several factors may account for the higher observed rates of MRD-negative CR in these series compared with the small number of patients described herein. Patients on ibrutinib at time of leukapheresis in our study had received a median of 5 prior lines of therapy (range, 1-11 lines) and, as such, were heavily pretreated. In the report by Gill et al., patients who had achieved a PR following 6 months of ibrutinib were eligible for CTL119 infusion (42); responses to ibrutinib frequently deepen with ongoing therapy, and ongoing anti-CLL activity may have contributed to response. In the report by Gauthier et al., patients were additionally uniformly conditioned with Flu/Cy, which may have contributed to in vivo CAR T cell expansion (43). Longer-term follow-up for both series will be of interest to determine whether concurrent therapy with ibrutinib and CTL119 or JCAR014 earlier in the course of CLL will lead to high rates of durable MRD-negative CR.

In our study, CRS of all grades was common, but grade $>2$ CRS was observed in only 2 patients, despite the higher infused doses of $19-28 \mathrm{z}$ CAR T cells $\left(1.0 \times 10^{7} / \mathrm{kg}\right.$ to $\left.3.0 \times 10^{7} / \mathrm{kg}\right)$ compared with doses used in patients with R/R B-ALL $\left(1.0 \times 10^{6} / \mathrm{kg}\right.$ to $\left.3.0 \times 10^{6} / \mathrm{kg}\right)(44)$ and the high burden of CLL in many patients at the time of CAR T cell infusion. These observations suggest the risk of severe CRS may be related to the underlying malignancy, in addition to the infused CAR T cell dose and overall antigenic burden of disease. Reasons for greater severity of CRS observed in other reports of CD19-targeted CAR T cell therapy for R/R CLL may include added toxicity of IL-2 administration (12) and greater peak CAR T cell expansion (45) compared with that observed in the present series. Neurologic toxicity was also uniformly reversible and grade $>2$ in only 2 patients, in contrast to the higher rates of grade 3-4 neurologic toxicity observed in patients with R/R B-ALL and diffuse large B cell lymphoma (18, 21-25, 46). Defects in T cell function and proliferation in patients with CLL may also limit CAR T cell function in vivo and the resulting severity of toxicity (29-33). Nevertheless, one early death was considered possibly related to CRS (27), 2 patients developed reversible grade 3 encephalopathy, and grade 2 CRS was common. The risk of these significant toxicities needs to be weighed against the possibility of deep and sustained CR in medically fit patients with R/R CLL, particularly in light of alternative well-tolerated emerging therapies for R/R CLL, including next-generation BTK inhibitors and combination therapies utilizing BCL2 inhibitors.

This study has several notable limitations, including the extended period over which the study enrolled patients and the small size as well as heterogeneity in patient characteristics, conditioning chemotherapy, and CAR T cell doses within the context of this phase I study. Many patients were enrolled prior to widespread availability of ibrutinib for treatment of R/R CLL, which may have served as effective salvage therapy before or after CAR T cell infusion. Only a handful of patients with B-NHL are included in this analysis; these data are principally intended to provide pilot data regarding safety. Additionally, many of the patients who signed informed consent never proceeded to undergo leukapheresis, CAR T cell product manufacturing, or CAR T cell infusion (Figure 1). In many cases, patients were exploring multiple therapeutic options at our center and others without committing to treatment with 19-28z CAR T cells and, ultimately, elected to pursue or continue alternative therapy. We are also unable to report herein on the subgroup of patients receiving 19-28z CAR T cells in addition to another cellular therapy or enrolled patients for whom the leukapheresis product was ultimately used to manufacture CAR T cells for an alternative clinical trial. Given the above considerations, we did not consider an intent-to-treat analysis as the most informative representation of our experience, and the results are presented for patients receiving 19-28z CAR T cells rather than for all patients enrolled; we recognize the proportion of patients achieving CR accordingly represents an even smaller fraction of enrolled compared with treated patients.

In summary, administration of conditioning chemotherapy and 19-28z CAR T cells was acceptably tolerated in heavily pretreated patients with R/R CLL at CAR T cell doses 10 -fold higher $\left(3 \times 10^{7} / \mathrm{kg}\right)$ than maximum tolerated doses in patients with B-ALL $\left(1-3 \times 10^{6} / \mathrm{kg}\right)$. Toxicities of CAR T cell infusion were largely manageable across a range of conditioning chemotherapy regimens, including Flu/ $\mathrm{Cy}$, and in combination with ibrutinib, though subgroups of patients experienced more severe toxicity (grade $\geq 3$ CRS, $10 \%$; grade 3 neurologic toxicity, 10\%). Three of twelve (25\%) evaluable CLL patients achieved CR, and in 2 patients, complete molecular response was sustained on extended follow-up. 
Achievement of deeper lymphodepletion may enhance in vivo CAR T cell expansion in forthcoming studies. While the clinical effect of concurrent ibrutinib therapy at the time of leukapheresis and/or CAR T cell administration remains uncertain, given the potential of this approach to augment CAR T cell expansion ex vivo and its tolerability, continuation of ibrutinib (in patients with an appropriate indication) during $\mathrm{T}$ cell collection and infusion appears to be appropriate in the context of ongoing clinical studies, and further investigation may clarify the implications of this approach. We and others are investigating further strategies to enhance the activity of CD19-targeted CAR T cell therapy, including further engineering of CD19-targeted CAR T cells to express additional costimulatory ligands (e.g., 4-1BBL, CD40L) (47-49) or secrete immunoregulatory cytokines (e.g., IL-12, IL-18) (50-52) or via extrinsic (53) or cell-intrinsic checkpoint blockade (54); ongoing studies of these novel approaches will aid in optimizing this therapeutic modality for patients with R/R CLL.

\section{Methods}

Clinical study. We conducted a single-center, nonblinded, phase I clinical trial (NCT00466531) to assess the safety and maximum tolerated dose of CD19-targeted CAR T cells in patients with R/R CLL and indolent B-NHL. Patients were recruited from Memorial Sloan Kettering Cancer Center (MSK) clinics; some had self-referred to MSK clinics or had been referred by outside providers aware of the study. Patients with R/R CLL and indolent B-NHL were eligible (Supplemental Table 6). CAR T cell products were infused inpatient at MSK between June 2007 and April 2017. Patients were followed, samples and imaging studies were obtained, and data were collected in the inpatient and outpatient settings at MSK. The data cutoff date was November 29, 2018. This study was conducted in multiple stages, as depicted in Figure 1.

In stage 1 of the study, patients received a single CAR T cell infusion $\left(1.2 \times 10^{7}\right.$ to $3.0 \times 10^{7} \mathrm{CAR} \mathrm{T}$ cells $/ \mathrm{kg}$ ) without antecedent conditioning chemotherapy.

In stage $2 \mathrm{~A}$, the study was modified to include Cy conditioning chemotherapy prior to CAR $\mathrm{T}$ cell infusion. The first patient (patient 4) received a single dose of $1.5 \mathrm{~g} / \mathrm{m}^{2}$ Cy conditioning chemotherapy followed by an infusion of $3.0 \times 10^{7} \mathrm{CAR} \mathrm{T}$ cells $/ \mathrm{kg}$. The clinical course of this patient, who died within 48 hours of infusion, has been previously described extensively (27). This severe AE was conservatively attributed as possibly related to the treatment, and as such the subsequent 3 patients were treated with a reduced CAR T cell dose in stage $2 \mathrm{~B}$. These 3 patients received a single dose of $1.5 \mathrm{~g} /$ $\mathrm{m}^{2} \mathrm{Cy}$ conditioning chemotherapy followed by CAR T cell infusion $\left(0.40 \times 10^{7}\right.$ to $1.0 \times 10^{7} \mathrm{CAR} \mathrm{T}$ cells $/ \mathrm{kg}$ ). As an additional measure to mitigate risk of severe toxicity, CAR T cells were administered as a split dose, with one-third of the planned total CAR T cell dose administered on day 0 , and the remaining dose administered the next day if the patient remained clinically stable without evidence of hypotension, renal failure, or dyspnea.

In stage 3, patients received the investigator's choice of conditioning chemotherapy followed by splitdose CAR T cell infusion, as above (total dose, $3 \times 10^{7} \mathrm{CAR} \mathrm{T}$ cells $/ \mathrm{kg}$ ). In addition, in this stage, the study was modified to include patients with subtypes of R/R indolent B-NHL (Table 2) and to permit ongoing therapy with ibrutinib at the time of autologous $\mathrm{T}$ cell collection and CAR $\mathrm{T}$ cell infusion (Supplemental Figure 1). Of note, patients with residual CLL following therapy, including ongoing therapy with ibrutinib, were eligible, including patients on ibrutinib with residual CLL, even without overt progression on ibrutinib. In patients on ibrutinib prior to CAR T cell infusion, ibrutinib was either held immediately prior to CAR $T$ cell infusion and then resumed after resolution of any acute after infusion toxicities or was continued through the time of CAR T cell infusion, at the discretion of the investigator.

The maximum tolerated dose was defined as the highest dose of CAR T cells with a DLT rate of $<33 \%$ out of 6 patients. A DLT was defined as any AE (see Supplemental Table 1) occurring within 30 days from the last infusion of $19-28 \mathrm{z}$ CAR T cells. The primary objective was to assess the safety of $19-28 \mathrm{z}$ CAR $\mathrm{T}$ cells with or without conditioning chemotherapy. Secondary objectives included assessment of disease response and CAR T cell persistence. Toxicities were assessed using the Common Terminology Criteria for Adverse Events (CTCAE) v3.0 through 2009 and subsequently assessed using v4.0. CRS was graded per criteria in Supplemental Table 2. Per an agreement with another institution, we do not report here the results of treatment for 5 patients receiving 19-28z CAR T cells in addition to another cellular therapy product.

All patients received levetiracetam as seizure prophylaxis beginning 2 days prior to CAR T cell infusion. Patients were permitted to receive subsequent infusions of $19-28 \mathrm{z}$ CAR T cells with or without conditioning chemotherapy at the discretion of the investigator. 
Generation and expansion of genetically modified T cells. PB leukocytes were obtained from enrolled patients by leukapheresis, and CAR-modified T cells were produced and released as previously described (16, 19, 55). Briefly, the leukapheresis product was washed and cryopreserved. T cells from the thawed leukapheresis product were isolated and activated with Dynabeads Human T-Activator CD3/CD28 magnetic beads (Invitrogen) and transduced with gammaretroviral 19-28z vector stocks. Transduced T cells were then further expanded with the Wave bioreactor to achieve the desired CAR T cell dose. EOP CAR T cell products were characterized immunophenotypically by FACS using commercially available antibodies (see Supplemental Table 7 for information on antibodies) (Table 3).

Assessment of 19-28z CAR T cell persistence. Persistence of 19-28z CAR-modified T cells in patient $\mathrm{PB}$ and BM was assessed by FACS using biotinylated goat antimouse IgG F(ab')2 (Jackson ImmunoResearch) and by qPCR to determine vector copy number $(16,19)$. Selected samples after infusion were tested after brief expansion of $\mathrm{T}$ cells in vitro in the presence of Dynabeads ClinExVivo CD3/CD28, as we have previously described $(16,19)$. In such patients, detection of CAR T cells is noted qualitatively only and is not depicted in Figure 4.

Analysis of cytokine profiles following 19-28z CAR T cell infusion. Serial serum samples were obtained before and after administration of conditioning chemotherapy and following CAR T cell infusion. Cytokine profiles were analyzed using the Luminex FlexMAP 3D system and Millipore's Human 38plex Cytokine Magnetic Bead Panel (16, 19, 20).

Response assessment. Clinical responses for patients with CLL were assessed using the IWCLL criteria at 3 months and 6 months following CAR T cell infusion on the basis of clinical examination, laboratory findings, BM aspirate, and biopsy analysis and, where appropriate, cross-sectional imaging studies, including computed tomography scans (56). Reduction in BM infiltrate or B-lymphoid nodules by $\geq 50 \%$ without full satisfaction of IWCLL criteria for PR or progression of disease was additionally considered to represent objective response (BM PR) with official classification as SD by IWCLL criteria. For patients with other B-NHL, responses were assessed by Revised Criteria for Response Assessment (Lugano Classification) (57). The presence of MRD was assessed by multiparameter flow cytometry and PCR-based (BIOMED-2) or next-generation sequencing-based (LymphoTrack) IgH clonality assays (InVivoScribe).

Statistics. Sample size for the phase I portion of the trial was determined based on a modified $3+3$ design, as described above in Clinical study. The effects of the study treatment were analyzed in individuals as above. EFS was defined as the time from day 1 of CAR T cell infusion to the date progression was established or until death from any cause and was assessed using Kaplan-Meier methods. Overall survival was estimated from the same start date and followed until death from any cause. Patients were censored at the date of the last follow-up. Continuous variables were compared between 2 independent groups using the Wilcoxon-Mann-Whitney test (rank-sum test). A $P$ value of less than 0.05 was considered significant. For cytokine analysis, the maximal fold increase was measured from baseline on day 1 of CAR T cell infusion to peak value within 1 month of CAR T cell infusion. Levels of 39 cytokines were measured, of which 12 were analyzed but not adjusted for multiple comparisons. The lower and upper limits of detection were used to determine fold change when measured values were above or below these limits. In 1 patient without evaluable cytokine levels on day 1 of CAR T cell infusion, the baseline level was defined on the day of conditioning chemotherapy. One patient died within 48 hours of CAR T cell infusion and was therefore considered nonevaluable for response.

Statistical analyses were performed with SAS 9.4 (SAS Institute) and Prism v7.01 (GraphPad).

Study approval. The institutional review board at MSK reviewed and approved this trial. All patients enrolled and treated on this trial provided written informed consent prior to participation. All clinical investigation was conducted according to the principles of the Declaration of Helsinki.

\section{Author contributions}

MBG performed the research, analyzed the results, and wrote the paper. IR performed the research and analyzed the results. BS performed the research, analyzed the results, and wrote the paper. XW, YW, TJP, EH, YB, and DGVL performed the research. MH and SMD analyzed the results. MS designed the research. MLP designed and performed the research. JHP and RJB designed and performed the research, analyzed the results, and wrote the paper. All authors critically reviewed the paper. 


\section{Acknowledgments}

This research was funded in part through NIH/NCI Cancer Center Support Grant P30 CA008748. MBG received funding from the Lymphoma Research Foundation, the NIH/National Center for Advancing Translational Sciences (UL1TR00457), and a American Society of Hematology Scholar Clinical Fellow Award. IR received funding from NIH/National Cancer Institute Cancer Center Support Grant (P30CA08748). JHP received funding from the Conquer Cancer Foundation of ASCO, a Leukemia and Lymphoma Society Career Development Grant, the Geoffrey Beene Cancer Foundation, a National Comprehensive Cancer Center Young Investigator Award, and an American Society of Hematology Scholar Junior Faculty Award. RJB received funding from the NIH/National Cancer Institute (R01 CA13873801), the Damon Runyon Clinical Investigator Award, a Translational and Integrative Medicine Fund Research Grant (MSK), the Annual Terry Fox Run for Cancer Research (New York, New York, USA) organized by the Canada Club of New York, the Carson Family Charitable Trust, Kate's Team, William H. Goodwin and Alice Goodwin, the Commonwealth Cancer Foundation for Research and the Experimental Therapeutics Center of MSK, the Geoffrey Beene Cancer Foundation, and the Bocina Cancer Research Fund. Editorial support in the preparation of this manuscript was provided by Hannah Rice.

Address correspondence to: Renier J. Brentjens, 1275 York Avenue, New York, New York 10065, USA. Phone: 212.639.7053; Email: brentjer@mskcc.org.

1. Kipps TJ. Chronic lymphocytic leukemia. Curr Opin Hematol. 2000;7(4):223-234

2. Howlader N, et al, eds. SEER Cancer Statistics Review, 1975-2014. https://seer.cancer.gov/csr/1975_2014/. Updated April 2, 2019. Accessed April 2, 2019.

3. Thompson PA, et al. Fludarabine, cyclophosphamide, and rituximab treatment achieves long-term disease-free survival in IGHV-mutated chronic lymphocytic leukemia. Blood. 2016;127(3):303-309.

4. Rossi D, et al. Molecular prediction of durable remission after first-line fludarabine-cyclophosphamide-rituximab in chronic lymphocytic leukemia. Blood. 2015;126(16):1921-1924.

5. Tam CS, et al. Long-term results of the fludarabine, cyclophosphamide, and rituximab regimen as initial therapy of chronic lymphocytic leukemia. Blood. 2008;112(4):975-980.

6. Lin KI, et al. Relevance of the immunoglobulin VH somatic mutation status in patients with chronic lymphocytic leukemia treated with fludarabine, cyclophosphamide, and rituximab (FCR) or related chemoimmunotherapy regimens. Blood. 2009;113(14):3168-3171.

7. Stilgenbauer S, et al. Gene mutations and treatment outcome in chronic lymphocytic leukemia: results from the CLL8 trial. Blood. 2014;123(21):3247-3254.

8. Eichhorst B, et al. First-line chemoimmunotherapy with bendamustine and rituximab versus fludarabine, cyclophosphamide, and rituximab in patients with advanced chronic lymphocytic leukaemia (CLL10): an international, open-label, randomised, phase 3, non-inferiority trial. Lancet Oncol. 2016;17(7):928-942.

9. Mato AR, et al. Optimal sequencing of ibrutinib, idelalisib, and venetoclax in chronic lymphocytic leukemia: results from a multicenter study of 683 patients. Ann Oncol. 2017;28(5):1050-1056.

10. Mato AR, et al. Outcomes of CLL patients treated with sequential kinase inhibitor therapy: a real world experience. Blood. 2016;128(18):2199-2205.

11. Jain P, et al. Outcomes of patients with chronic lymphocytic leukemia after discontinuing ibrutinib. Blood. 2015;125(13):2062-2067.

12. Kochenderfer JN, et al. B-cell depletion and remissions of malignancy along with cytokine-associated toxicity in a clinical trial of anti-CD19 chimeric-antigen-receptor-transduced T cells. Blood. 2012;119(12):2709-2720.

13. Kochenderfer JN, et al. Chemotherapy-refractory diffuse large B-cell lymphoma and indolent B-cell malignancies can be effectively treated with autologous T cells expressing an anti-CD19 chimeric antigen receptor. J Clin Oncol. 2015;33(6):540-549.

14. Grupp SA, et al. Durable remissions in children with relapsed/refractory ALL treated with $\mathrm{T}$ cells engineered with a CD19-targeted chimeric antigen receptor (CTL019). Blood. 2015;126(23):681.

15. Schuster SJ, et al. Sustained Remissions Following Chimeric Antigen Receptor Modified T Cells Directed Against CD19 (CTL019) in Patients with Relapsed or Refractory CD19+ Lymphomas. Blood. 2015;126(23):183.

16. Brentjens RJ, et al. Safety and persistence of adoptively transferred autologous CD19-targeted T cells in patients with relapsed or chemotherapy refractory B-cell leukemias. Blood. 2011;118(18):4817-4828.

17. Turtle CJ, et al. Durable Molecular Remissions in Chronic Lymphocytic Leukemia Treated With CD19-Specific Chimeric Antigen Receptor-Modified T Cells After Failure of Ibrutinib. J Clin Oncol. 2017;35(26):3010-3020.

18. Geyer MB, et al. Autologous CD19-Targeted CAR T Cells in Patients with Residual CLL following Initial Purine Analog-Based Therapy. Mol Ther. 2018;26(8):1896-1905.

19. Brentjens RJ, et al. CD19-targeted T cells rapidly induce molecular remissions in adults with chemotherapy-refractory acute lymphoblastic leukemia. Sci Transl Med. 2013;5(177):177ra38.

20. Davila ML, et al. Efficacy and toxicity management of 19-28z CAR T cell therapy in B cell acute lymphoblastic leukemia. Sci Transl Med. 2014;6(224):224ra25.

21. Gardner RA, et al. Intent-to-treat leukemia remission by CD19 CAR T cells of defined formulation and dose in children and young adults. Blood. 2017;129(25):3322-3331.

22. Lee DW, et al. T cells expressing CD19 chimeric antigen receptors for acute lymphoblastic leukaemia in children and young 
adults: a phase 1 dose-escalation trial. Lancet. 2015;385(9967):517-528.

23. Maude SL, et al. Chimeric antigen receptor T cells for sustained remissions in leukemia. N Engl J Med. 2014;371(16):1507-1517.

24. Turtle CJ, et al. CD19 CAR-T cells of defined CD4+:CD8+ composition in adult B cell ALL patients. J Clin Invest. 2016;126(6):2123-2138.

25. Maude SL, et al. Tisagenlecleucel in Children and Young Adults with B-Cell Lymphoblastic Leukemia. N Engl J Med. 2018;378(5):439-448.

26. Kochenderfer JN, et al. Eradication of B-lineage cells and regression of lymphoma in a patient treated with autologous $\mathrm{T}$ cells genetically engineered to recognize CD19. Blood. 2010;116(20):4099-4102.

27. Brentjens R, Yeh R, Bernal Y, Riviere I, Sadelain M. Treatment of chronic lymphocytic leukemia with genetically targeted autologous T cells: case report of an unforeseen adverse event in a phase I clinical trial. Mol Ther. 2010;18(4):666-668

28. Turtle CJ, et al. Immunotherapy of non-Hodgkin's lymphoma with a defined ratio of CD8+ and CD4+ CD19-specific chimeric antigen receptor-modified T cells. Sci Transl Med. 2016;8(355):355ra116.

29. Fraietta JA, et al. Ibrutinib enhances chimeric antigen receptor T-cell engraftment and efficacy in leukemia. Blood. 2016;127(9):1117-1127.

30. Ramsay AG, Clear AJ, Fatah R, Gribben JG. Multiple inhibitory ligands induce impaired T-cell immunologic synapse function in chronic lymphocytic leukemia that can be blocked with lenalidomide: establishing a reversible immune evasion mechanism in human cancer. Blood. 2012;120(7):1412-1421.

31. Görgün G, Holderried TA, Zahrieh D, Neuberg D, Gribben JG. Chronic lymphocytic leukemia cells induce changes in gene expression of CD4 and CD8 T cells. J Clin Invest. 2005;115(7):1797-1805.

32. McClanahan F, et al. PD-L1 checkpoint blockade prevents immune dysfunction and leukemia development in a mouse model of chronic lymphocytic leukemia. Blood. 2015;126(2):203-211.

33. Riches JC, et al. T cells from CLL patients exhibit features of T-cell exhaustion but retain capacity for cytokine production. Blood. 2013;121(9):1612-1621.

34. Sagiv-Barfi I, Kohrt HE, Czerwinski DK, Ng PP, Chang BY, Levy R. Therapeutic antitumor immunity by checkpoint blockade is enhanced by ibrutinib, an inhibitor of both BTK and ITK. Proc Natl Acad Sci USA. 2015;112(9):E966-E972.

35. Bachmann MF, Wolint P, Schwarz K, Jäger P, Oxenius A. Functional properties and lineage relationship of CD8+ T cell subsets identified by expression of IL-7 receptor alpha and CD62L. J Immunol. 2005;175(7):4686-4696.

36. Mahnke YD, Brodie TM, Sallusto F, Roederer M, Lugli E. The who's who of T-cell differentiation: human memory T-cell subsets. Eur J Immunol. 2013;43(11):2797-2809.

37. Wolint P, Betts MR, Koup RA, Oxenius A. Immediate cytotoxicity but not degranulation distinguishes effector and memory subsets of CD8+ T cells. J Exp Med. 2004;199(7):925-936.

38. Unsoeld H, Pircher H. Complex memory T-cell phenotypes revealed by coexpression of CD62L and CCR7. J Virol. 2005;79(7):4510-4513.

39. Wirth TC, Badovinac VP, Zhao L, Dailey MO, Harty JT. Differentiation of central memory CD8 T cells is independent of CD62L-mediated trafficking to lymph nodes. J Immunol. 2009;182(10):6195-6206

40. Sommermeyer D, et al. Chimeric antigen receptor-modified $\mathrm{T}$ cells derived from defined CD8+ and CD4+ subsets confer superior antitumor reactivity in vivo. Leukemia. 2016;30(2):492-500.

41. Fraietta JA, et al. Determinants of response and resistance to CD19 chimeric antigen receptor (CAR) T cell therapy of chronic lymphocytic leukemia. Nat Med. 2018;24(5):563-571.

42. Gill S, et al. CD19 CAR-T cells combined with ibrutinib to induce complete remission in CLL. J Clin Oncol. 2017;35(15 suppl):7509.

43. Gauthier J, et al. Comparison of Efficacy and Toxicity of CD19-Specific Chimeric Antigen Receptor T-Cells Alone or in Combination with Ibrutinib for Relapsed and/or Refractory CLL. Blood. 2018;132(Suppl 1):299.

44. Park JH, et al. Long-Term Follow-up of CD19 CAR Therapy in Acute Lymphoblastic Leukemia. N Engl J Med. 2018;378(5):449-459.

45. Porter DL, et al. Chimeric antigen receptor T cells persist and induce sustained remissions in relapsed refractory chronic lymphocytic leukemia. Sci Transl Med. 2015;7(303):303ra139.

46. Neelapu SS, et al. Axicabtagene Ciloleucel CAR T-Cell Therapy in Refractory Large B-Cell Lymphoma. $N$ Engl J Med. 2017;377(26):2531-2544.

47. Zhao Z, et al. Structural Design of Engineered Costimulation Determines Tumor Rejection Kinetics and Persistence of CAR T Cells. Cancer Cell. 2015;28(4):415-428.

48. Curran KJ, et al. Enhancing antitumor efficacy of chimeric antigen receptor T cells through constitutive CD40L expression. Mol Ther. 2015;23(4):769-778.

49. Park JH, et al. A Phase I First-in-Human Clinical Trial of CD19-Targeted 19-28z/4-1BBL "Armored" CAR T Cells in Patients with Relapsed or Refractory NHL and CLL Including Richter's Transformation. Blood. 2018;132(Suppl 1):224.

50. Avanzi MP, et al. Engineered Tumor-Targeted T Cells Mediate Enhanced Anti-Tumor Efficacy Both Directly and through Activation of the Endogenous Immune System. Cell Rep. 2018;23(7):2130-2141.

51. Pegram HJ, et al. Tumor-targeted T cells modified to secrete IL-12 eradicate systemic tumors without need for prior conditioning. Blood. 2012;119(18):4133-4141.

52. Pegram HJ, et al. IL-12-secreting CD19-targeted cord blood-derived T cells for the immunotherapy of B-cell acute lymphoblastic leukemia. Leukemia. 2015;29(2):415-422.

53. John LB, et al. Anti-PD-1 antibody therapy potently enhances the eradication of established tumors by gene-modified T cells. Clin Cancer Res. 2013;19(20):5636-5646.

54. Chen N, Morello A, Tano Z, Adusumilli PS. CAR T-cell intrinsic PD-1 checkpoint blockade: A two-in-one approach for solid tumor immunotherapy. Oncoimmunology. 2017;6(2):e1273302.

55. Hollyman D, et al. Manufacturing validation of biologically functional T cells targeted to CD19 antigen for autologous adoptive cell therapy. J Immunother. 2009;32(2):169-180.

56. Hallek M, et al. Guidelines for the diagnosis and treatment of chronic lymphocytic leukemia: a report from the International 
Workshop on Chronic Lymphocytic Leukemia updating the National Cancer Institute-Working Group 1996 guidelines. Blood. 2008;111(12):5446-5456.

57. Cheson BD, et al. Recommendations for initial evaluation, staging, and response assessment of Hodgkin and non-Hodgkin lymphoma: the Lugano classification. J Clin Oncol. 2014;32(27):3059-3068. 